\title{
Fear conditioning and extinction as a function of escape from black to white vs. escape from white to black
}

\author{
GARY E. BROWN, ROD GUTHRIE, and PAUL BLAES \\ University of Tennessee at Martin, Martin, Tennessee 38238
}

\begin{abstract}
In the present experiment one group of rats was trained to escape from the black compartment to the white compartment of a shuttlebox and another group was trained to escape from the white compartment to the black compartment using a modification of the usual acquired fear procedure. There was no difference between the two groups on preshock trials, or on acquisition trials. The only reliable differences were in extinction latencies and trials to extinction; the white to black group had shorter latencies of escape in extinction and took nearly twice as many trials to extinguish, indicating that the association between white and fear and black and safety in the usual acquired fear study may not be entirely acquired.
\end{abstract}

According to Miller (1948, 1951), fear can be acquired as a response to a previously neutral stimulus. Once acquired, this fear can act as a drive and motivate the learning of a new response. In Miller's (1948) experiment, rats were shocked in the white compartment of a two-compartment shuttlebox and allowed to escape to the black compartment. After the shock trials, shock was omitted and the animals continued to run. Next, the conditions were changed so that the door separating the two compartments could be opened if the rat turned a wheel in the white compartment. The rats learned to operate the wheel to escape from the white compartment without further shocks. Presumably, the white compartment elicited internal fear cues and when the rat escaped, the fear was reduced; therefore, the response was learned and maintained.

The fear response in this situation may not have been entirely acquired. As Miller (1951) points out, certain stimuli may have what he calls a "latent tendency" to elicit fear. Using Miller's example, the rabbit in Watson and Rayner's (1920) study that was used as a CS and paired with a loud noise as the US may have had some "inherent capacity" to frighten the child. As Miller points out, support for this idea comes from Bregman's (1934) failure to replicate Watson and Rayner's results when other neutral objects, such as blocks of wood, were used as the CS. In addition, in clinical situations one generally sees acquired fears (phobias) to potentially hazardous objects such as knives, snakes, height, etc. rather than "neutral" objects.

Even though Miller reported that the rats showed no initial preference for either compartment, there is reason to suspect that the fear was not entirely acquired and this his results would have been different had he

This manuscript is sponsored by H. E. Marks, who takes full editorial responsibility for its contents. controlled for the color of the shuttlebox compartments and run a control group from the black compartment to the white compartment. Several studies show that in several different experimental situations, rats prefer black over white (Dember \& Fowler, 1959; Douglas, 1966; Freedman, 1965; Allison, Larson, \& Jenson, 1967). Allison et al. found that rats had shorter latencies in escapting from the white to black compartment of a shuttlebox than the black to white compartment regardless of whether or not they had received shock in the start compartment. The animals were not run to extinction.

In the present experiment one group of rats was trained to escape from the black compartment to the white compartment in a shuttlebox and another group was trained to escape from the white compartment to the black compartment using a modification of the usual acquired fear procedure. All animals were then run to extinction. The specific hypothesis being tested was that the rats run from the white to black compartment should acquire this response more readily and extinguish more slowly because the associations between black and safety and white and fear are not entirely acquired.

\section{METHOD}

\section{Subjects}

The subjects were 20 naive male albino rats obtained from the Holtzman Company. They were all approximately 90 days old at the time of the experiment.

\footnotetext{
Apparatus

A two-compartment shuttlebox which measured $131 / 2 \times 7 \times 10$ in. was used. One compartment was painted black, and one white; the roof was made of Plexiglas. The two compartments were separated by a guillotine door which started a Standard Electric Timer when raised. On shock trials, the guillotine door was raised and 2-mA shock was automatically delivered through the grid floor of the start compartment. A contact relay was connected to the grid floor and the timer in
} 


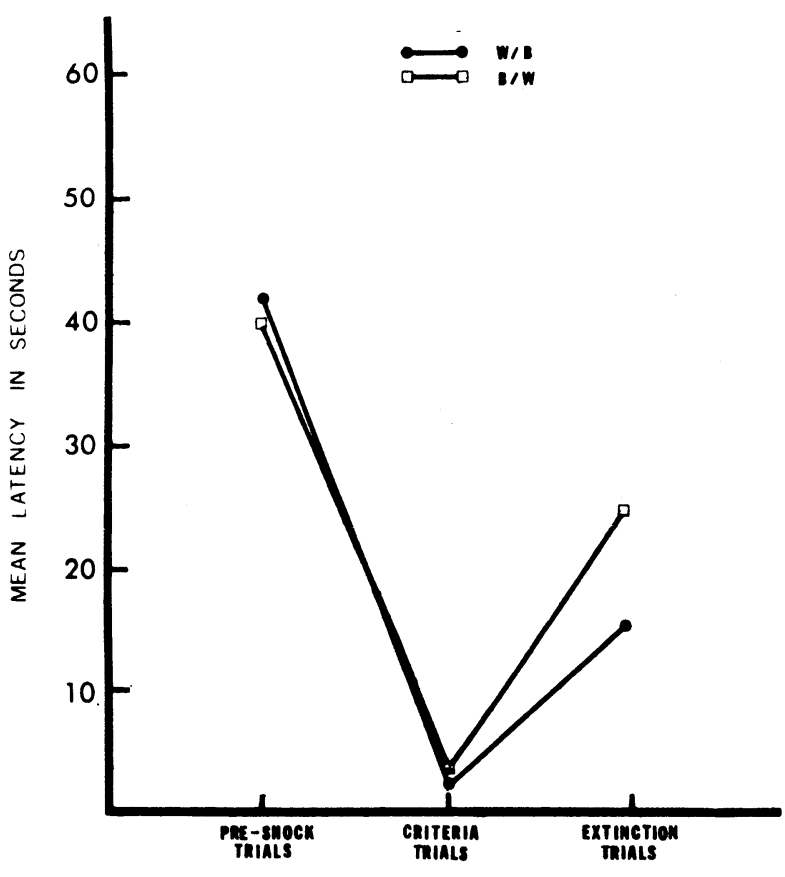

Figure 1. Mean latencies during preshock trials, criteria trials and extinction trials. The only significant difference between the two groups occurred in the extinction trials.

order to automatically record the latency of crossing from one compartment to the other.

\section{Procedure}

The subjects were randomly assigned either to a group that was always run from the black compartment to the white compartment (BW) or to a group that was always run from the white compartment to the black compartment (WB). On the first day of the experiment all subjects were given 10 trials without shock. The subject was placed in either the black or the white compartment, depending on its groups, and the door was raised. If the subject did not cross to the other compartment, the door was lowered and the subject was allowed to remain there for approximately $30 \mathrm{sec}$. Then the subject was returned to the start compartment for the next trial.

On Day 2 each subject was again placed in the apparatus, and the previous day's procedure was followed on Trial 1. However, on Trial 2 when the door was raised, the subject recived a $2-\mathrm{mA}$ shock which he could escape by running to the other side. The door was lowered and the subject was allowed to remain in the "safe" side for $30 \mathrm{sec}$ after which he was returned to the start compartment. On Trial 3, no shock was delivered and if the subject escaped to the "safe" compartment within $60 \mathrm{sec}$, no shock was delivered on Trial 4. If the subject failed to escape within $60 \mathrm{sec}$ on any trial, then the door was lowered for approximately $30 \mathrm{sec}$ and the subject received shock on the next trial. This procedure was followed until each subject reached a criteria of escaping in under $60 \mathrm{sec}$ on 10 consecutive trials. After this criteria was reached, no more shock were delivered and the subjects were given 10 trials a day until they extinguished. The subjects were considered extinguished if they did not escape in $60 \mathrm{sec}$ on 6 of the 10 daily trials.

\section{RESULTS}

As can be seen in Figure 1, there was no significant difference in the latencies between the two groups during the 10 preshock trials or in the latencies on 10 criteria trials. The only significant difference in latencies was during extinction; the black to white group was reliably slower than the white to black group $(p<.05)$.

As can be seen in Table 1, the two groups each received the same number of shocks and there was no difference in the duration of shock each group received. In addition, there was no difference in the number of trials to criterion; however, there was a reliable difference in the number of extinction trials $(p<.05)$.

\section{DISCUSSION}

The only noticeable differences between the two groups in the present study took place in extinction. Apparently, during the acquisition the association between the white compartment and shock was as easily acquired as the association between the black compartment and shock. Zerbolio (1968) also found no differences in the number of trials to criterion in a one-way avoidance task between a group run from a black compartment to a white compartment and a group run from a white compartment to a black compartment. However, Allison et al (1967) found rats had shorter latencies in escaping from white to black than black to white in a one-way avoidance task. regardless of whether or not they had been shocked in the start compartment. Most of the other studies (Dember \& Fowler, 1959; Freedman, 1965; Douglas, 1966) which reported that rats preferred black to white used a T-maze to measure black or white preference.

Table 1

Mean Number of Shocks, Mean Shock Duration (or Mean Latency of Escape on Shock Trials), Mean Number of Trials to Criteria (10 Consecutive Escapes Under $60 \mathrm{Sec}$ Without Shock), and Mean Number of Trials to Extinction. The only significant difference between the two groups was in the trials to extinction.

\begin{tabular}{|c|c|c|c|c|}
\hline$B / W$ & 2.0 & 3.3 & 13.6 & 40.0 \\
\hline W/B & 2.0 & 2.1 & 13.8 & 77.0 \\
\hline & $\begin{array}{l}\text { Mean No. } \\
\text { of Shocks }\end{array}$ & $\begin{array}{c}\text { Mean Shock } \\
\text { Duration }\end{array}$ & $\begin{array}{l}\text { Mean No. of } \\
\text { Trials to } \\
\text { Criteria }\end{array}$ & $\begin{array}{l}\text { Mean No. of } \\
\text { Trials to } \\
\text { Extinction }\end{array}$ \\
\hline
\end{tabular}


One would expect from several recent reviews of the literature on the comparative aspects of learning (Bolles, 1973; Shettleworth, 1973; Seligman, 1970) that rats would more easily acquire the association between black and safety since in their natural environment rats are nocturnal animals and when faced with danger, take refuge in dark places; however, such was not the case in Zerbolio's (1968) experiment or in the present experiment. On the other hand, in the present experiment once the association between black and safety was acquired, it did remain in the rat's behavior repertoire longer than the association between white and safety indicating that the association between black and safety was not entirely acquired. Possibly comparing the latencies during acquisition as most studies have done is not as sensitive a measure of fear as is resistance to extinction.

Probably, in view of the equivocal results in experimental situations with rats involving black-white discrimination, it would be wise to run a color control group. This is seldom done. For example, Gruber (1970) tested the effect of visual cues in a one-trial passive avoidance response. He placed the subject in the white compartment of a shuttlebox; the door was then raised and the subject was allowed to cross into the black compartment where it received an inescapable shock. The animals were then tested by having one-half of the subjects run to a black compartment and one-half to a white compartment. There was no difference in the latencies. It would have been interesting to have a group of subjects run from a black compartment to a white compartment where they received shock and then compared their latencies to black or white. The animals shocked in the black compartment may not have avoided that compartment because of a predisposition to associated black with safety.

\section{REFERENCES}

Allison, J., Larson, D., \& Jenson, D. D. Acquired fear, brightness preference, and one-way shuttlebox performance. Psychonomic Science, 1967, 8, 269-270.

Bolles, R. C. The comparative psychology of learning: The selective association principle and some problems with "general", laws of learning. In Bermant, G. (Ed.), Perspectives on animal behavior. Glenview, Ill: Scott, Foresman, 1973.

Bregman, E. An attempt to modify the emotional attitude of infants by the conditioned response technique. Journal of Genetic Psychology, 1934, 45, 169-168.

Dember, W. N., \& Fowler, H. Spontaneous alternation after free and forced trials. Canadian Journal of Psychology, 1959, 13 , 151-154.

Douglas, R. J. Cues for spontaneous alternation. Journal of Comparative Physiological Psychology, 1966, 62, 171-183.

Freedman, P. E. Habituation of alternation behavior. Journal of Experimental Psychology, 1965, 69, 613-617.

Gruber, R. P. Effect of visual cues on 1-trial passive avoidance response. Psychonomic Science, 1970, 18, 34 .

Miller, N. E. Studies of fear as an acquirable drive: I. Fear as Motivation and fear-reduction as reinforcement in the learning of new responses. Journal of Experimental Psychology, 1948, 38, 89-101.

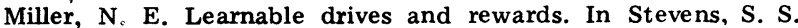
(Ed.), Handbook of experimental psychology. New York: Wiley, 1951

Shettlew orth, S. J. Constraints on learning. In Lehrman, D. S., Hinde, R. A., \& Shaw, E. (Eds.), Advances in the study of behavior, 4. New York: Academic Press, 1972.

Seligman, M. E. P. On the generality of the laws of learning. Psychological Review, 1970, 77, 406-418.

Watson, J. B., \& Rayner, R. Conditioned emotional reactions Journal of Experimental Psychology, 1920, 3, 1-14.

Zerbolio, D. J., Jr. Escape and approach responses in avoidance learning. Canadian Journal of Psy chology, 1968, 22, 60-71.

(Received for publication January 25, 1975.) 